\title{
Results of Interlaboratory Test Programs to Assess the Precision of Inclusion Ratings by Methods A, C and D of ASTM E45
}

\author{
George F. Vander Voort ${ }^{1}$ \\ 1. Consultant - Struers Inc.
}

Over the years, ASTM Committee E-4 on Metallography has conducted interlaboratory test programs to evaluate the precision and bias associated with measurements of microstructure using proposed and existing test methods. ASTM decided in the late 1970s that all test methods that generated numerical data must have a precision and bias section defining the repeatability and reproducibility of the method. Defining bias associated with a test method is difficult unless there is an absolute known value for the quantity being measured and this is not possible when microstructural features are being measured. This paper shows the results for an interlaboratory test using Method A, "worst field" ratings of inclusions in steels using the original Plates I and III of ASTM E-45, using Method C, a worst field rating using Plate II; and, using Method D, a quantitative approach where every field is rated using Plates I and III. The results from 9 people who were reported to be qualified, regular users of the method revealed consistent problems of misclassification of inclusions types and a wide range of severity ratings for each specimen. The test results using an image analyzer will be compared to that of the manual raters.

ASTM E45 was created in 1942 and was based on an earlier [1, 2] chart developed by Jernkontoret in Sweden. The charts were designed to determine the size, distribution, number and types of indigenous inclusions (naturally occurring particles that form before or during solidification due to limited solid solubility for $\mathrm{O}$ and S) in steels. Originally, E45 included 3 charts, Plates I, II and III, but now there are two, Plates 1r and II. Plate 1r replaced Plates I and III after these charts were measured [3] and corrected in the creating of the image analysis method for making E45 JK inclusion ratings [4, 5] published as E1122 in 1992, which was incorporated into E45 in 2006. The JK chart, the original Plate I, categorized indigenous inclusions by morphology (previous studies had demonstrated clearly that composition must also be a classification criterion) as: sulfides (type A), aluminates (type B), silicates (type C) and globular oxides (type D), although the classification at the time of this study was stated to be only by morphology. There were thin and thick categories of each type based on their thickness (or diameter for the D types) and the severity ratings varied in whole increments from 1 to 5 . Plate III was similar but the severity limits were in 0.5 increments from 0.5 to 2.5 .

The data from this round robin (which is in general agreement with previous studies, although previous studies had substantial problems with raters not following the rules of the round robin) clearly shows that ASTM E45 chart ratings are neither precise nor reproducible. Repeatability was not evaluated in this study. The overall problem stems from a number of factors, as listed above, which make chart ratings undependable. Yes, they are fast and simple to do, but they are highly subjective and the results appear to be of rather limited value. This study revealed numerous misclassifications of inclusion types. The ratings by the 9 experienced metallographers were not reproducible between operators. In general the precision of the $\mathrm{B}$ and $\mathrm{D}$ type inclusions were better than for the $\mathrm{A}$ and $\mathrm{C}$ type inclusions.

Basing the categorization of $\mathrm{A}$ and $\mathrm{C}$ types on morphology alone creates inherent confusion in ratings as both types look similar being elongated malleable inclusions. These charts did not show the gray level difference between gray sulfides and darker, blackish, glassy-looking silicates. Because of this, it is not 
surprising that some raters seemed to confuse the two types regularly in their ratings. Obviously, sulfides and silicates have markedly different effects upon the performance of steel products. Similar charts for rating inclusions have been developed by numerous countries and companies over the years [3] and by ISO and at least two such charts do depict sulfides as being lighter than silicates. The tips of sulfides also appear to be more rounded than silicates which appear to be sharper. But, these differences may be difficult to see at the usual depiction of the inclusions at $100 \mathrm{X}$ magnification by the chart pictures.

In general, the precision of the thin ratings were better than the precision of the thick inclusion ratings, regardless of the inclusion types. Steels rated to Plate I (severities of 0 to 5 in 1.0 severity steps) were poorer ( $\sim 2$ at the higher severity ratings) while steels rated using Plate III (severities of 0 to 2.5 in 0.5 severity steps) were a bit better ( $\sim 1$ at the highest severity ratings).

The precision of inclusion ratings using Method $\mathrm{C}$ were also subject to misclassification problems and poor reproducibility between experienced raters. Plate II covers only two inclusion types, rather than four, and has the widest severity range of any chart. Terminology related to the $\mathrm{O}$ and $\mathrm{S}$ types of oxides is confusing and needs improvement. Severity levels of oxides up to 8 would seem to be of rare applicability with today's steels.

\section{References:}

[1] B. Rinman et al., "Inclusion Chart for the Estimation of Slag Inclusions in Steel," Jernkontoret, Stockholm, Sweden, Uppsala (1936), 24 pages.

[2] B. Rinman et al., Jernkontoret Ann., Vol. 120, 1936, pp. 199-226.

[3] G. F. Vander Voort, "Inclusion Measurement," Metallography as a Quality Control Tool, Plenum Press, NY, 1980, pp. 1-88.

[4] G. F. Vander Voort and J. F. Golden, Microstructural Science, Vol. 10, Elsevier Science Publishing Co., NY, 1982, pp. 277-290.

[5] C. Forget, Micon 90: Advances in Video Technology for Microstructural Control, ASTM STP 1094, ASTM, Philadelphia, 1991, pp. 135-150. 